\title{
A Teoria da Ação Comunicativa de Habermas e suas Aplicações nas Organizações: Contribuições para uma Agenda de Pesquisa
}

\author{
Habermas' Theory of Communicative Action and its Applications in Organizations: \\ Contributions to a Research Agenda
}

Isabella Francisca Freitas Gouveia de Vasconcelos ${ }^{1}$

Yvon Pesqueux ${ }^{2}$

Alvaro Bruno Cyrino ${ }^{3}$

\section{Resumo}

Neste ensaio teórico apresentamos elementos da Teoria da Ação Comunicativa de Habermas e a comparamos com a abordagem do poder de Michel Crozier. Discutimos uma possível agenda de pesquisa e apresentamos os artigos selecionados para este número especial da revista.

Palavras-chave: Teoria da Ação Comunicativa. Poder. Pesquisa.

\begin{abstract}
In this theoretical essay, we introduce elements of Habermas' Theory of Communicative Action and compare it to Michel Crozier's approach to power. We discuss a possible research agenda and introduce the articles selected for this special issue of the journal.
\end{abstract}

Keywords: Theory of Communicative Action. Power. Research.

\footnotetext{
Artigo submetido em 02 de julho de 2014 e aceito em 08 de agosto de 2014.

DOI: http://dx.doi.org/10.1590/1679-395131417

${ }^{1}$ Doutora em Administração pela HEC - Ecole dês Hautes Etudes Commerciales, França; Professora Dra. Adjunta da EBAPE/FGV; Professora associada e pesquisadora do LIRSA- Laboratorio Interdisciplinaire de Recherches en Sciences de L'Action, CNAMParis/França e Coordenadora do Centro Franco-Brasileiro de Estudos Avançados em Organizações, Inovação e Sustentabilidade. Endereço: Praia de Botafogo, 190 - 5o andar - Botafogo, CEP 22250-900, Rio de Janeiro, RJ - Brasil. E-mail: isabella.vasconcelos@fgv.br

${ }^{2}$ Doutor em Economia pela Universidade de Paris I; Professor Dr. titular do CNAM - Consevatoire National des Arts et Métiers, CNAMParis/França; Pesquisador e professor titular do LIRSA - Laboratoire Intercisciplinaire de Recherche en Sciences de L'Action, CNAMParis/França. Endereço: 292 Rue Saint Martin, Paris - França. E-mail:yvon.pesqueux@cnam.fr

${ }^{3}$ Doutor em Estratégia e Política de Empresas pela HEC - Ecole de Hautes Etudes Commerciales, França; Vice-diretor e Professor Dr. Adjunto da EBAPE/FGV. Endereço: Praia de Botafogo, 190 - 5 Andar - Botafogo, CEP 22250-900, Rio de Janeiro, RJ - Brasil. E-mail: alvaro.cyrino@fgv.br
} 


\section{Apresentação}

Como vimos no artigo "Teoria da Ação Comunicativa e responsabilidade social empresarial: uma proposta de pesquisa" (VASCONCELOS e PESQUEUX, 2013a), nossa proposta de pesquisa visa a explorar nas organizações as possibilidades de uma comunicação estruturada com base na Teoria da Ação Comunicativa de Habermas. Retomamos a temática neste ensaio teórico para o número especial da revista, dedicado a essa discussão teórica.Como vimos, questões ligadas à Ética nas empresas e à definição de agendas de desenvolvimento sustentável, à responsabilidade social corporativa e às propostas de inovação tecnológica e, ainda, à gestão da pesquisa e do desenvolvimento constituem as áreas das empresas onde as práticas de comunicação de inspiração habermasiana podem ocorrer. Entretanto, vale notar que muitos autores salientam que tal aplicação é possível em todas as áreas da empresa. É extremamente válido discutir aspectos substantivos ligados à inovação sustentável, à pesquisa e ao desenvolvimento, às agendas de desenvolvimento da organização, do setor ou da sociedade sem estar limitados a interesses pessoais, alianças estratégicas entre grupos ou interesses relacionados a poder. Desse tipo de comunicação, no qual se procura estruturar um diálogo baseado em uma primeira instância de ideias sobre critérios como desenvolvimento tecnológico, social e humano, de maneira desprendida sem levar em conta interesses pessoais ou de grupos, ao menos em uma primeira instância, podem nascer pautas de desenvolvimento que realmente baseiem suas propostas em critérios como desenvolvimento tecnológico e humano e façam a diferença para o sistema organizacional e para a sociedade como um todo. É claro que quando tratamos de eficiência e eficácia dos sistemas organizacionais, devemos considerar questões como limitação de recursos, competitividade, ação estratégica e alianças de poder, inerentes aos sistemas organizacionais vistos como sistemas culturais e políticos. Porém, essas questões deveriam vir à tona quando tratamos da operacionalização de decisões relativas às pautas de desenvolvimento. Estas deveriam ser fixadas de forma mais independente de considerações relativas a interesses políticos de grupos e de coalisões políticas na organização, baseando-se em questões de caráter mais geral e tendo em vista o desenvolvimento tecnológico e social, função última das empresas e organizações que atuam em dado setor da economia.

Passaremos agora a comparar duas abordagens diferentes, mas que podem ser complementares: A proposta da estruturação de fóruns de comunicação de inspiração habermasiana nas organizações, para a proposição de pautas de desenvolvimento e, mais tarde, considerações de ordem menos geral e mais operacional que levam em conta questões como a coordenação sistemas políticos e culturais que são as organizações tendo em vista aspectos de eficiência e eficácia.

Como vimos no artigo "Teoria da Ação Comunicativa e responsabilidade social empresarial: uma proposta de pesquisa" (VASCONCELOS e PESQUEUX, 2013a), que serve de referência para esta chamada de trabalhos, como muitas iniciativas teóricas, a denominada Ética da Comunicação (ou Teoria da Ação Comunicativa) baseia-se nos estudos da Escola de Frankfurt, cuja atividade principal era realizar uma reflexão filosófica e política sobre a sociedade alemã anterior e posterior ao nazismo.

A dimensão crítica fundamental dessa escola conduziu alguns de seus autores (Adorno e Horkheimer) a uma concepção pessimista da sociedade contemporânea.

Eles viam sinais de não concretização de um projeto fundamental, o projeto da modernidade, do Iluminismo. Esse fracasso da chamada era racional foi expresso pelo triunfo passageiro e trágico do nazismo. A queda dos valores fundamentais ligados ao Iluminismo, provocada pelo nazismo, trouxe a crise da razão, a ideia de que "não se podia pensar mais depois de Auschwitz".

Essa foi uma das questões centrais da Escola de Frankfurt.

Dessa forma, a história mostrava que a irracionalidade tinha sido a última palavra em matéria de pensamento. Sob esse ponto de vista, para muitos autores, o genocídio confirmava o fracasso da visão racional do mundo, o que foi expresso de forma clara na declaração de Horkheimer (apud VASCONCELOS e PESQUEUX, 2013b, p. 5): "nós não sabemos mais onde está a justiça, mas nós sabemos 
onde está o mal". Trata-se da crise da racionalidade e da metafísica, pois a razão fica reduzida à instrumentalidade, ao positivismo e ao cientificismo, pretendendo ser neutra do ponto de vista axiológico, apenas reconhecendo valores como os de eficiência e de utilidade.

"A razão é calculista. Ela pode estabelecer verdades de fato e relações matemáticas, mas nada mais. Na prática, ela apenas pode falar dos meios. Com respeito aos fins, ela deve se calar." (VASCONCELOS e PESQUEUX, 2013b). Habermas A crise da razão se manifesta em dois aspectos: um seria fundamentado, mas neutro, e o outro ético (pressuposto kantiano), mas de ordem subjetiva, e, então, não verdadeiramente legítima. Dessa forma, na proposta da Teoria da Ação Comunicativa, não é possível uma reflexão racional individual para o estabelecimento de objetivos e valores moralmente válidos. A Teoria da Ação Comunicativa de Habermas propõe que razão e a ética estarão reunidas de forma legítima. A Teoria da Ação Comunicativa propõe a recuperação da racionalidade humana por meio da intersubjetividade, da estruturação de uma comunicação que pretende obedecer a critérios de justiça e verdade.

Assim que um debate se instaura, os interlocutores reconhecem implicitamente a existência de valores como a verdade dos fatos, a justiça dos atos e a sinceridade dos julgamentos. Se o interlocutor recusa a referência a esses princípios, a comunicação se torna impossível. Da mesma forma que na moral kantiana, a possibilidade de mentira destruiria toda moral.

Os princípios fundamentais da ética pressupõem, então, a existência de uma comunicação entre diferentes sujeitos ao termo de uma discussão bem conduzida. Não se tem ética sem comunicação e sem comunicação autêntica. A Teoria da Ação Comunicativa reúne, assim, ética e comunicação intersubjetiva dentro de um princípio de tolerância, democracia e ação política. Para que a ação comunicativa ocorra, além de seguir as regras de legitimidade explicitadas acima, que devem ser aceitas pelo grupo social que interage, é fundamental que os membros do grupo que se comunica o façam com base em um princípio de igualdade de direitos. Como diz Apel (1987, p. 94), "é esta exigência de um reconhecimento recíproco das pessoas como sujeitos de uma argumentação lógica e não apenas o uso lógico correto da capacidade de compreensão do indivíduo que justifica que se fale de uma "ética da lógica"." 4

Dessa forma, analisando as diversas formas de comunicação, pode-se depreender quais fundamentos morais embasaram essa comunicação.

Dessa forma, a filosofia moral tem a função de depreender a ética subjacente a cada forma de comunicação. No entanto, segundo Habermas, atualmente, a função dos filósofos não é determinar em termos absolutos quais são os comportamentos a adotar em tal ou qual situação.

Tendo em vista o pluralismo totalmente justificado dos projetos e das diversas formas de vida, os filósofos não podem mais dar instruções universalmente válidas sobre o sentido da vida. Como filósofos, resta-lhes a atitude de análise reflexiva do procedimento graças ao qual se pode responder em geral às questões éticas. Ou seja, às formas de comunicação que conduzem à formulação de uma ética pelo grupo social. O significado do que representa um comportamento moral e antes de tudo moral, nós o apreendemos antes de toda filosofia. Isso ocorre em nossa piedade com relação à integridade ofendida de outro da mesma forma no sofrimento em relação à própria identidade ferida ou no medo que acompanha o ataque a esta forma de identidade. As experiências próprias à socialização primária relativas à proteção, à ajuda solidária e à equidade impregnam nossas intuições e nos educam bem mais do que poderiam fazer todos os argumentos possíveis. ${ }^{5}$

\footnotetext{
${ }^{4}$ K.O.Apel. L'éthique à l'âge de la science, PUL, Lille, 1987, p.94.

${ }^{5}$ J.Habermas. Éthique de la discussion, Cerf, Paris 1992, pp. 164-165.
} 
O filósofo não pretende, dessa forma, ditar ao homem comum sua moral. Esta existe já em seus atos antes de toda análise filosófica e ética. Kant também já havia constatado isso. A Filosofia, no entanto, tem a tarefa de compreender os pressupostos da moral e seus critérios de legitimidade, os quais vão além das diversas formas de racionalidade, fazendo apelo a uma exigência de universalidade. Assim, pode ser respondida pelo filósofo a questão "quais são os critérios de legitimidade que produzem a comunicação entre os membros de um dado grupo social que produzirá o que é considerado ético para este grupo?”.

Tendo em vista que o questionamento do filósofo acerca da ética da discussão se situa ao nível dos critérios de legitimidade, então, duas grandes questões se colocam: se os critérios de legitimidade da comunicação foram seguidos e se é possível sua aplicação e sua realização (relação que existe entre pressupostos, princípios fundadores e realidade da ação moral).

Em um primeiro momento, na organização, pode-se fazer o exercício de estruturar a comunicação dentro desses princípios para que se fixem pautas de desenvolvimento sustentável, inovação sustentável, pesquisa e desenvolvimento, código de ética, benefícios e programas voltados à qualidade de vida dos membros da comunidade aos quais a empresa está ligada (inclusive da sociedade), todas decisões de caráter geral que obedecem a certos princípios universais. Após isso, instauram-se pressões para que se tomem decisões de caráter mais operacional, que levam em conta elementos de poder na organização. Comparando com a abordagem acima, para tratar de questões relativas a poder, utilizaremos a teoria de poder ligada a Michel Crozier, um dos principais teóricos da Escola de Poder. ${ }^{6}$

A ideia, pois, é que fóruns de discussão de inspiração habermasiana podem ser criados para permitir uma comunicação estruturada de forma mais isenta no que se refere a interesses de poder - uma comunicação mais "pura" que leve em conta critérios como desenvolvimento humano, social e tecnológico; que obedeça a critérios científicos, a critérios voltados à justiça social, valores ligados ao desenvolvimento das comunidades às quais a organização está ligada. Desse tipo de comunicação podem nascer pautas de desenvolvimento para a empresa, a organização ou o setor. Em um segundo momento, quando se tratar de questões ligadas à operacionalização dessas pautas de desenvolvimento, surgem critérios ligados à eficiência técnica e à coordenação de equipes e, nesse momento, surgem questões ligadas a interesses de departamentos, grupos, e alianças estratégicas. Optamos pela teoria de Michel Crozier para fazer um contraponto nesse sentido.

\section{A Proposta Crozieriana de Aprendizagem Coletiva}

Em se tratando de aprendizagem e inovação, Crozier e Friedberg (1981) falam de uma nova lógica que domina as organizações, na qual a capacidade de inovar e de transformar torna-se mais decisiva que a capacidade de racionalizar que dominava os modelos anteriores.

A lógica "consumo de massa - produção" perde seu domínio para a lógica "alta tecnologia - serviços", na qual a qualidade do serviço é que fará a diferença. Essa qualidade não depende apenas de inovações tecnológicas, mas, primordialmente, da capacidade de mobilização dos diversos parceiros da organização. Crozier e Friedberg (1981) fundamentam suas ideias no que denominam um "novo" conceito de ação coletiva, segundo o qual a capacidade de mudança - que está no cerne do processo de aprendizagem decorre da capacidade das pessoas cooperarem de forma eficaz e gerarem transformação.

Segundo Crozier e Friedberg (1981), a mudança nas organizações é uma questão sociológica, pois são as pessoas que mudam, mas não passivamente, isso ocorre dentro da coletividade e como uma coletividade, não

${ }^{6}$ Escola de Análise Estratégica das Organizações. 
individualmente. Para Crozier e Friedberg (1981), a criação do futuro, o desenvolvimento das organizações é, antes de tudo, baseado na transformação das pessoas que as compõem, o que se dá a partir da aprendizagem dessas pessoas. Os autores entendem essa aprendizagem não só como um processo que se dá pelos métodos formais, mas, também, como um processo de ensaio e erro. Crozier e Friedberg (1981) entendem que a aprendizagem implica uma mudança não só nas regras do jogo, mas na própria natureza do jogo dentro do tecido social que configura as organizações.

Esse tecido social é composto de relações, interações e trocas organizadas, no qual a aprendizagem se dá de forma coletiva e se efetua no cotidiano das relações. No entanto Crozier e Friedberg (1981) reconhecem que a mudança - base da inovação - não é um processo natural.

$\mathrm{Na}$ verdade ela constitui um problema para as organizações, exatamente por seu caráter coletivo. Para os autores, a aprendizagem só pode ser compreendida como um processo de criação coletiva, por meio do qual os membros de certa coletividade - por ensaio e erro - inventam e fixam novas formas de jogar o jogo social da cooperação e do conflito. Trata-se, pois, de um processo de aprendizagem que não pode ser individual, e é esse o ponto que leva à sua dificuldade. Cada um dos participantes desse "jogo" pode aprender rapidamente novas formas de jogo, mas o dificultador é a aprendizagem de grande parte dos atores organizacionais, esta, sim, fundamental ao processo de inovação de que depende a evolução das organizações preconizada pela teoria das capacidades dinâmicas. Essa aprendizagem de todos os atores implica a aquisição de novos modelos relacionais.

\section{Aprendizagem e Inovação}

Reinventar as regras do jogo coletivo como base da aprendizagem organizacional vai além da simples mudança de comportamentos.

Implica um questionamento mais profundo dos padrões cognitivos e técnicos vigentes, uma análise crítica de procedimentos organizacionais que permite a criação de um novo conjunto de referências. Podemos associar essa capacidade de aprendizagem àquela definida por Argyris (2000) como a aprendizagem de circuito duplo (double loop learning).

Para o autor, a aprendizagem se dá quando erros são detectados e corrigidos ou quando ocorre a coincidência entre a intenção das ações e suas consequências.

Há, para ele, duas formas de correção de erros: uma baseada na simples mudança de comportamentos (single looping learning) e outra baseada na mudança do que ele denomina "programa mestre", que os indivíduos utilizam para produzir suas ações (double looping learning, ou aprendizagem em circuito duplo). Esses "programas mestres", segundo Argyris (2000), podem ser entendidos como teorias de ação concreta que informam os atores sociais sobre as estratégias que eles devem utilizar para alcançar suas intenções. Argyris (2000) pontua que as teorias de ação concreta são conduzidas por um conjunto de valores que delineia o arcabouço das ações.

O autor identifica duas teorias de ação concreta: aquela que o indivíduo esposa, suas crenças, valores e atitudes, e aquela que o indivíduo realmente emprega - a teoria em uso. O processo de aprendizagem em circuito duplo está associado à mudança desses padrões, crenças e pressupostos, e não apenas dos comportamentos. Do ponto de vista do indivíduo, esse processo de mudança é mais facilmente obtido, como ressaltam Motta e Vasconcelos (2003), quando envolve valores e padrões desenvolvidos a partir da socialização secundária, aquela desenvolvida a partir das relações do indivíduo com a sociedade, e com os quais os indivíduos possuem um grau de identificação menor do que com aqueles desenvolvidos a partir da 
socialização primária (que ocorre na primeira infância) e que preestruturam a percepção e integram a personalidade de cada um.

Do ponto de vista das organizações, a aprendizagem de circuito duplo envolve o acesso às informações que permitem comparar o que existe no mercado, a competitividade, os modelos de negócio dos concorrentes, a estrutura organizacional vigente, para, em seguida, questionar essa estrutura e propor ações corretivas, de modo a inserir mudanças na estrutura antiga, se for o caso, aprimorando competências, desenvolvendo um novo modelo de negócios.

Isso significa, segundo Argyris (2000), corrigir erros primeiramente mudando os valores subjacentes e, só então, as ações, o que demanda uma ruptura. No seio das organizações, pois, o processo de aprendizagem em circuito duplo demanda uma mudança que desestrutura determinado sistema de ação concreta para reconstruir outro - daí a ruptura. De acordo com Argyris (2000), o processo de aprendizagem não ocorre quando os indivíduos aceitam os jogos vigentes e omitem os erros organizacionais, o que para ele é o mais comum nas organizações.

Portanto, Argyris (2000) comunga a visão de Crozier e Friedberg (1981) sobre a dificuldade inerente aos processos de mudança. Confrontar padrões de forma mais profunda pode levar a conflitos, que normalmente são evitados pelos próprios jogos organizacionais. Argyris (2000) comenta até a existência de certos jogos que se prestam exatamente ao papel de ocultar outros jogos, dificultando, assim, os questionamentos mais profundos que levariam ao processo de aprendizagem em circuito duplo. Em resumo, fazendo uma relação entre as posições de Argyris (2000) e Crozier e Friedberg (1981), chegamos à seguinte conclusão: os indivíduos vivem nas organizações em sistemas de ação concreta onde estão configuradas certas técnicas e tecnologias (vistas como as melhores no sistema) e certas formas de gerência, práticas sociais próprias à gestão de pessoas (formas de trabalho, comportamento, alianças estratégicas etc.). Assim, em uma organização, podem predominar formas de trabalho individualistas, nas quais as pessoas tenham muito apego à regra e às normas e trabalhem em torno de uma tecnologia específica.

Inovação, para Argyris (2000), implica aprendizagem de circuito duplo, como acima definido, ou seja, o questionamento de regras e normas vigentes e a proposição de um novo sistema social e uma nova técnica que desafiem os pressupostos de base do modelo anterior.

A aprendizagem, por sua vez, implica mudança de comportamentos, formas relacionais, tecnologias, serviços etc. Esses conceitos não podem ser dissociados. Porém, quando mudam as tecnologias (quando ocorre a inovação de produtos e serviços), muitas vezes também mudam as formas de gestão da organização.

O que anteriormente era visto como positivo passa a ser visto como inadequado, obsoleto etc. A organização pode implantar novos softwares, formas de serviço, e, para tanto, implementar novas formas de gestão e exigir dos indivíduos novas formas de comportamento (trabalho em equipe, autonomia etc.). Os indivíduos, habituados aos padrões de comportamento anteriores que "davam certo", poderão ter, muitas vezes, dificuldades para se adaptar às novas formas relacionais e adotar os novos comportamentos exigidos pelo novo sistema organizacional (pelo novo "sistema de ação concreta"). Portanto, como afirmam Crozier e Friedberg (1981), em se tratando de inovação, a aprendizagem não é só técnica, ela também é relacional aprendizagem de novas formas de interação social, adoção de novas formas de comportamento, adoção de novas alianças estratégicas.

Um indivíduo que antes trabalhava bem de maneira isolada pode ter dificuldades para se adaptar a um novo modo de trabalho em equipe. A constituição de um novo sistema de ação concreta acompanha o processo de inovação. É importante considerar que o indivíduo pode ser "vencedor" e ter uma posição de prestígio e sucesso no antigo sistema organizacional por conhecer técnicas consideradas fundamentais para a organização. No entanto, no processo de inovação e aprendizagem e desenvolvimento de novas competências técnicas que passarão a embasar o futuro da organização, esse indivíduo que antes detinha as competências responsáveis pelo sucesso na organização deverá inserir-se no novo sistema, renegociando 
suas posições, encontrando uma posição e desenvolvendo novas alianças estratégicas. Se ele não fizer isso, perderá posições e prestígio e poderá ser fonte de resistência à mudança, por não aceitar "perder" e transformar-se em um fracasso no novo sistema. Tendo desenvolvido uma identidade social na organização, durante anos, de "vencedor", terá dificuldades e sofrerá com a ruptura do sistema, o que motivará sua resistência. A mudança, assim, não é algo simples, pois implica ruptura sistêmica, reconstrução de jogos de poder, construção de novas alianças políticas e novas formas identitárias. A mudança brusca pode, inclusive, provocar no indivíduo anomia (perda das normas de referência) e grande sofrimento. Dada essa condição, a desdramatização da mudança e a inserção de indivíduos na empresa que tenham habilidade de negociar e transformar-se ao mesmo tempo que a organização o faz, evoluindo, passa a ser uma competência valorizada nos indivíduos por essa corrente, que fala em identidades evolutivas, tanto da organização quanto do indivíduo. Se a mudança é difícil, por implicar ruptura, a construção de um novo sistema organizacional, dizem esses autores, só se faz a partir das competências e das práticas anteriores, pois mesmo que a mudança envolva, por exemplo, despedida em massa de funcionários, muitos dos atores sociais deverão permanecer, e estes deverão reciclar seus conhecimentos e desenvolver novas competências para continuar no novo sistema.

Há dificuldades, no entanto, no aprendizado de novas competências.

Segundo Crozier e Friedberg (1981), os atores sociais que detêm o conhecimento de certa técnica fundamental para a organização, por meio da qual esta ganha dinheiro, detêm o controle do que se costuma denominar "zona de incerteza pertinente". Assim, uma expertise ou um conhecimento técnico difícil de ser adquirido e que garanta o sucesso financeiro da organização confere aos atores sociais que detêm este conhecimento mais poder e prestígio no sistema organizacional, enquanto esse conhecimento for fonte de ganho financeiro para a Firma. Quando se inovam produtos e serviços, mudam-se as competências essenciais da Firma, e, consequentemente, mudam as zonas de incerteza pertinente (as competências fundamentais que fazem diferença para a organização). Na maioria das vezes, os antigos grupos organizacionais, detentores das antigas competências, que controlavam a partir destas as antigas zonas de incerteza pertinentes, perdem poder e novos grupos organizacionais, detentores do novo conhecimento útil para a organização, ganham poder, pois passam a controlar as novas zonas de incerteza pertinente. Como vimos, fenômenos de resistência à mudança são, assim, normais, pois os atores sociais perderão poder e prestígio devido à inovação. Novas articulações políticas e alianças estratégicas deverão ser feitas em torno das novas competências válidas para o sistema. Os atores sociais detentores dos antigos conhecimentos válidos no sistema anterior poderão adquirir novos conhecimentos válidos no novo sistema organizacional e articular-se em torno das novas competências técnicas válidas no novo sistema, passando, também, a controlar as novas zonas de incerteza pertinente, como faziam no passado.

Isso, porém, exige esforço para adquirir as novas habilidades, bem como articulação política e negociação com os novos grupos emergentes no sistema. Cabe à gestão estratégica de pessoas promover os arranjos organizacionais necessários à transformação do sistema, atuando como facilitadora desses processos. Essas zonas de incerteza são as que os indivíduos procuram dominar na busca de suas estratégias e podem estar relacionadas ao domínio exclusivo de diferentes tipos de recursos, como pontuam Crozier e Friedberg (1981):

- ao domínio de competências específicas;

- ao domínio de relações com parceiros sociais críticos;

- ao domínio das informações e dos processos de comunicação; e

- ao domínio das regras organizacionais fundamentais.

Dominar uma zona de incerteza, seja ela de qual natureza for, é fundamental no jogo de poder das organizações. 
Logo, podemos depreender que é da natureza dos atores organizacionais buscar a perpetuação de suas zonas de incerteza como forma de dominar os jogos a seu favor. Essa conclusão reforça a dificuldade de mudança que vimos anteriormente e pode limitar a capacidade de aprendizagem e inovação. Como colocam Crozier e Friedberg (1981), a dificuldade da mudança está intimamente relacionada ao fato dos atores sociais serem "prisioneiros" dos sistemas de ação que dominam e que lhes garantem o controle sobre determinadas zonas de incerteza. Crozier e Friedberg (1981) tratam de uma lógica estratégica de ação, na qual os indivíduos negociam posições, interesses, criando estruturas de jogo win-win, na melhor das hipóteses, na qual tanto os indivíduos como as organizações ganhem. Trata-se de um modelo que considera o indivíduo um ator político que negocia recursos escassos na organização em torno de posições de poder.

A conciliação dessas duas visões na organização - a ideia da estruturação de fóruns de inspiração habermasiana para fixação do conteúdo de pautas de desenvolvimento social, tecnológico e humano e a utilização de abordagens mais pragmáticas, tendo em vista a abordagem crozieriana e a ideia de ação estratégica para questões operacionais, parece-nos gerar uma agenda de pesquisas extremamente interessante, pois permite a implementação, mesmo em organizações com fins lucrativos, de fóruns de comunicação de inspiração habermasiana para fixação de pautas gerais de desenvolvimento, coadunando essa visão, muitas vezes criticada por ser extremamente teórica e idealista, com questões de caráter mais pragmático, com a análise crozieriana, que aqui poderia ser utilizada para a implementação dessas pautas de desenvolvimento e para a consideração de questões operacionais. Evita-se, dessa forma, o paradoxo entre uma visão idealista, considerada teórica, e uma visão denominada "realista", que leva em conta jogos de poder e alianças estratégicas.

O fórum apresenta artigos que trazem considerações que exploram a visão habermasiana, questões ligadas à sustentabilidade, ao desenvolvimento sustentável e à inovação em geral.

Os artigos publicados aqui são os seguintes:

"Estratégia como prática social e teoria da ação comunicativa: possíveis aproximações teóricas", no qual Elisa Zwick, Isabel Cristina da Silva e Mozar José de Brito reúnem os conceitos de Estratégia como Prática Social e a Teoria da Ação Comunicativa de Habermas, estabelecendo relações teóricas entre essas proposições e as interfaces de pesquisa que podem ser estabelecidas. Trata-se de uma proposta inovadora no que tange à ideia de aproximar uma visão teórica da estratégica, cujo caráter é essencialmente pragmático, a uma proposição teórica, como a habermasiana.

No artigo "Institucionalização das iniciativas socioambientais das organizações: interfaces entre a teoria do desenvolvimento social de Habermas e o isomorfismo da teoria institucional", Martinho Luis Kelm, Cíntia Lisiane da Silva Renz, Sérgio Luís Allebrandt e Jorge Oneide Sausen abordam a importante Teoria Neoinstitucional, muito utilizada em nosso país na análise organizacional, e, de forma inovadora, buscam conciliar essa abordagem teórica com a Teoria do Desenvolvimento Social de Habermas, em uma proposição teórica que leva em conta as interfaces conceituais entre as duas proposições e como é possível encontrar elementos comuns que permitam conciliar essas ideias, constituindo uma nova forma de análise das organizações.

No artigo "Uma aproximação entre pragmática universal e economia solidária: o caso de Catende", Fábio Gomes busca uma aproximação teórica entre os conceitos de Economia Solidária desenvolvidos por Paul Singer e os conceitos ligados à racionalidade comunicativa habermasiana. Para tanto, aplica esses constructos teóricos em um estudo de caso relativo ao Projeto Harmonia, no município de Catende, em Pernambuco. $\mathrm{O}$ artigo, além de contribuir com a aproximação de duas abordagens teóricas como as citadas, proporcionando, assim, uma contribuição original, permite a aplicação desses conceitos na análise de um estudo de caso, o que ilustra de forma concreta a contribuição teórica proposta. 
No artigo "Valores relativos à competição organizacional e ação comunicativa: um novo olhar sobre o fazer organizacional", Silvia Marcia Russi De Domenico e Maria Luisa Mendes Teixeira apresentam um estudo realizado em uma empresa coligada ao projeto Economia de Comunhão na Liberdade. As autoras analisam o conceito de competição organizacional como fruto de um equilíbrio dinâmico que ora privilegia ações estratégicas, ora privilegia ações que buscam o entendimento. $\mathrm{O}$ conceito de comunicação que busca $\mathrm{o}$ entendimento fundamenta-se na proposta de uma comunicação estruturada de acordo com os princípios propostos por Habermas na Teoria da Ação Comunicativa e diferencia-se da chamada ação estratégica. A contribuição do artigo ao propor um equilíbrio dinâmico entre essas duas questões como cerne da atividade organizacional, ilustrando essa proposta por meio de um estudo empírico, constitui uma proposta original de pesquisa.

No artigo "Transparência e legitimação de objetivos institucionais em empresas estatais: um estudo de caso sobre a Petrobras", de Fernando Almeida Barbalho e Janann Joslin Medeiros, os autores discutem os objetivos estratégicos duplos das empresas estatais - financeiros e sociais - e como, tendo em vista esses objetivos, a Petrobras procura atender à necessidade de transparência organizacional, em uma dinâmica que traz desafios à sua implementação, como ilustra o estudo de caso.

No artigo "Ergologia: uma abordagem possível para os estudos organizacionais sobre trabalho", Edvalter Becker Holz e Mônica de Fátima Bianco apresentam a abordagem desenvolvida pelo filósofo Yves Schwartz sobre o trabalho. O artigo aborda em detalhe conceitos fundamentais dessa teoria e analisa pesquisas realizadas anteriormente, propondo uma agenda de futuras pesquisas. Ao propor uma agenda de pesquisas, os autores definem conceitos relativos à análise organizacional, mostrando como é possível conciliar a visão de Schwartz com conceitos teóricos típicos da análise organizacional.

No artigo "Integrando empresas e cooperativas de catadores em fluxos reversos de resíduos sólidos pós-consumo: o caso Vira-Lata", Jacques Demajorovic, Elisangela Ferreira Caires, Laudicéia Nunes da Silva Gonçalves e Maria Janilelly da Costa Silva mostram como possibilidades previstas na lei, no caso a Política Nacional de Resíduos Sólidos, que reconhece o trabalho dos catadores de materiais recicláveis, oferecem oportunidades de cooperação fundamental entre atores fundamentais da cadeia de reciclagem brasileira, como empresas, poder público e cooperativas de trabalhadores. Na prática, porém, a implementação dessas políticas oferece dificuldades e desafios fundamentais a ser superados para que se produzam bons resultados. $\mathrm{O}$ artigo analisa quais desafios seria fundamental superar para tornar viável a implementação dessa cooperação efetiva, contribuindo, assim, a partir da análise de um caso concreto, com propostas que permitem aprimorar as políticas de desenvolvimento sustentável do país.

No artigo "A percepção da informação e da sua relevância no cenário institucional: sob a perspectiva de gestores e líderes", de Eliane Vieira, aborda uma questão extremamente atual ao analisar como a informação é percebida no cenário organizacional em foco, no segmento de reflorestamento. O artigo utiliza conceitos de teoria da decisão, aplicando-os a um setor pouco estudado no qual valores como desenvolvimento sustentável e preservação do meio ambiente são fundamentais. A contribuição do artigo é, assim, analisar uma atividade pouco estudada, como o reflorestamento, que envolve valores ligados à preservação do ecossistema, utilizando esses conceitos e ferramentas de gestão.

Os artigos aprovados para este número especial da revista buscam utilizar os conceitos citados em análises que priorizam a Filosofia e os Estudos Organizacionais. Esperamos que a leitura desses estudos estimule os pesquisadores a avançar com pesquisas que busquem aproximar a Teoria da Ação Comunicativa de Habermas e outras correntes da Filosofia à análise organizacional. 


\section{Referências}

APEL, K. O. L'Éthique à l’âge de la science. Lille: PUF, 1987.

ARGYRIS, C. On organizational learning. Oxford: Blackwell, 2000.

CROZIER, M. ; FRIEDBERG, E. L’acteur et le système. Paris: PUF, 1981.

HABERMAS, J. Éthique de la discussion. Paris: Cerf, 1992.

MOTTA, F. C.; VASCONCELOS, I. F. F. G. Teoria geral da administração. São Paulo: Cengage, 2003.

VASCONCELOS, I. F. F. G.; PESQUEUX, Y. Teoria da ação comunicativa e responsabilidade social empresarial: uma proposta de pesquisa. Cadernos EBAPE.BR, v. 10, n. 1, p. 30-41, 2013 a.

VASCONCELOS, I. F. F. G.; PESQUEUX, Y. Habermas e a teoria da ação comunicativa: uma interpretação. Paris: Conservatoire National des Arts et Métiers, 2013b. Não publicado. 